\title{
A Case of Myocardial Rupture on the Background of Coronary Artery Thrombosis
}

\author{
Hirachan $\mathrm{N}^{1 *}$, Maharjan $\mathrm{M}^{2}$ \\ ${ }^{1}$ Lecturer, Department of Forensic Medicine, Gandaki Medical College \& Teaching Hospital, Pokhara, Nepal \\ ${ }^{2}$ Lecturer, Department of Forensic Medicine, MMC, IOM, Kathmandu, Nepal
}

\author{
Keywords \\ Coronary artery thrombosis, \\ myocardial rupture, \\ pericardial tamponade. \\ Corresponding author \\ *Dr. Neelu Hirachan $N$ \\ Lecturer, Department of Forensic \\ Medicine \\ Gandaki Medical College \& Teaching \\ Hospital, Pokhara, Nepal \\ Email:drneeluhirachan@gmail.com
}

\begin{abstract}
Myocardial infarction infrequently complicates with the rupture of myocardial free wall in $6.2 \%$ of cases. It represents the second cause of death after cardiogenic shock, and accounts for as much as $15 \%$ of in-hospital mortality. The authors here report a case of an 80 year old male with the cause of death as myocardial rupture on the background of coronary artery thrombosis.
\end{abstract}

\section{INTRODUCTION}

Myocardial infarction occurs when there is severe stenosis or complete occlusion of a coronary artery so that the blood supply is insufficient to maintain the oxygenation of the myocardium. However, if there is adequate collateral circulation, myocardium can still be viable. These ischemic myocardium can be further weakened by the process of cellular death and the inflammatory response to these necrotic cells. The area of the myocardial infarct is weakest between three days and one week after the clinical onset of the infarct and it is at this time that the weakened area of myocardium may rupture and cause sudden death from a haemopericardium and cardiac tamponade. The rupture occasionally occurs through the interventricular septum, resulting in a left-right shunt. If a papillary muscle is infarcted, it may rupture, which will allow part of the mitral valve to prolapse, which may be associated with sudden death or may present as a sudden onset of valve insufficiency. Usually an infarct heals by fibrosis. This can be the pavement sites for physiological or electrical dysfunction of the cardiac cells. Cardiac aneurysms may form at sites of infarction; they may calcify and they may rupture 4 . Coronary artery disease accounts for approximately $75 \%$ of all sudden deaths handled by most medical examiners. About $50 \%$ die suddenly; $25 \%$ die without any preceding history or warning. Mechanism of death usually a lethal cardiac arrhythmia; ventricular arrhythmia in $80 \%$ of cases and sudden asystole or bradyarrhythmia in about $20 \%$ of cases. For death to occur, the degree of stenosis is usually $75 \%$ or greater $^{5}$. Davies and Popple (1979) consider that 85\% stenosis is the minimum criteria of stenosis reasonably associated with sudden death ${ }^{6}$. Usually 75\% stenosis of the lumen is required to be designated significant occlusion. Myocardial perforation most commonly occurs during the first week, usually between four and seven days before connective tissue has had a chance to form 
adequately. By the end of two weeks, much of the necrotic muscle has been replaced by fibrous tissue ${ }^{7}$. Rupture of the free wall of the heart has been reported to be the cause of death in $4-13 \%$ of fatal cases of acute myocardial infarction ${ }^{8}$. Although cardiac rupture has an incidence of only $1 \%$ to $4 \%$ following a heart attack, it accounts for up to $20 \%$ of mortalities associated with infarction ${ }^{9}$.

\section{CASE PRESENTATION}

This case was of an 80 years old male who was found dead in his apartment on 2069/12/26. On the same day, the body was brought to Forensic Medicine Department, Teaching Hospital where the postmortem examination was performed. History relating to the deceased's medical, surgical, personal etc could not be extracted as the deceased was living alone. On external examination of the body, there was no any obvious fresh injury present over the body. On internal examination of the heart including pericardial cavity, the pericardial cavity contained an estimated $500 \mathrm{ml}$ of blood with blood clots. Pericardium was intact. Multiple ruptures of myocardial wall were present over anterior aspect of inter ventricular septum and inferior wall of left ventricle. Proximal portion of left anterior descending artery was calcified with $80 \%$ occlusion. Proximal two-third of the left circumflex artery was also calcified with $80 \%$ to $90 \%$ occlusion with atheromatous plaque. Additionally, a thrombus was present in the proximal portion of left circumflex artery. Right coronary artery appeared normal. On sectioning, diffuse fibrotic lesions were present over the interventricular muscles. Hemorrhagic patches were seen over the myocardium of posterior wall of left ventricle. The stomach contained an estimated $100 \mathrm{ml}$ of semi-digested egg chunks. Besides this, other systemic examinations of central nervous system, respiratory system, genitourinary and gastrointestinal systems appeared normal.

\section{DISCUSSION}

London and London found in a study of 1000 cases of fatal myocardial infarction that $50 \%$ of ruptures occurred within three days and $89 \%$ within 14 days. The anterior wall of the left ventricle is involved more commonly than the posterior wall ${ }^{8}$. Rupture of the free wall of the heart caused death within a very short time following rupture ${ }^{10}$. Clinical features which raise the suspicion of rupture of the heart include an abrupt decline of the arterial blood pressure and rapidly increasing venous distention. Van Torsel and Edwards, in reviewing 40 cases of cardiac rupture complicating acute myocardial infarction, presented evidence suggesting that the symptomatology in several patients was consistent with a gradual evolution of cardiac rupture ${ }^{11}$. Rupture of the midlateral wall was most common (32\%) and usually occurred in the setting of an inferoposterolateral infarction related to an acute left circumflex artery occlusion in a retrospective and prospective study of 70 patients with rupture done by Oliva et al. ${ }^{12}$ Among 26 cases of myocardial infarction with cardiac rupture (found in 6791 necropsies), 12 cases (63.0 percent) were due to occlusion of the left descending branch of the left coronary artery; three cases $(16 \%)$ were due to the occlusion of the circumflex branch of the left coronary artery; and four cases (21\%) were due to the right coronary artery ${ }^{13}$.

\section{CONCLUSION}

Myocardial infarction infrequently complicates with myocardial rupture. In such cases it leads to a higher risk of mortality due to hemodynamic compromise due to pericardial tamponade.

\section{REFERENCES}

1. López-Sendón J, González A, López de Sá E, ComaCanella I, Roldán I, Domínguez F et al. Diagnosis of subacute ventricular wall rupture after acute myocardial infarction: Sensitivity and specificity of clinical, hemodynamic and echocardiographic criteria. J Am Coll Cardiol. 1992; 19:1145-533.

2. Becker RC, Gore JM, Lambrew C, Weaver WD, Rubison RM, French WJ et al. A composite view of cardiac rupture in the United States National Registry of Myocardial Infarction. J Am Coll Cardiol. 1996; 27: 1321-6.

3. Purcaro A, Costantini C, Ciampani N, Mazzanti M, Silenzi C, Gili A et al. Diagnostic criteria and management of subacute ventricular free wall rupture complicating acute myocardial infarction. Am J Cardiol. 1997; 80:397-405.

4. Shepherd R. Simpson's Forensic Medicine: $12^{\text {th }}$ edition; 121-122.

5. DiMaio V.J.M, Dana S.E, Handbook of Forensic Pathology, Taylor and Francis Group: 2 $2^{\text {nd }}$ edition; 41. 
6. Vij K. Textbook of Forensic Medicine and Toxicology Principles and Practice, $4^{\text {th }}$ edition; 137-138.

7. Chapman A.J, Death and Deduction, 2nd edition; 370373.

8. London RE, London SB. Rupture of the heart critical analysis of 47 consecutive autopsy cases. Circulation. 1965; 31: 202.

9. Reddy SG, Roberts WC. Frequency of rupture of the left ventricular free wall or ventricular septum among necropsy cases of fatal acute myocardial infarction since introduction of coronary care units. Am J Cardiol. 1989; 63: 906-11.

10. Biorck G, Mogensen L, Nyquist 0, Orinuis E, Sjgren A.
Studies of myocardial rupture with cardiac tamponade in acute myocardial infarction: I. Clinical features. Chest. 1972; 61: 4.

11. Van Torsel RA, Edwards JE. Rupture of heart complicating myocardial infarction: Analysis of 40 cases including nine examples of left ventricular false aneurysm. Chest. 1972; 61: 104. 1972

12. Oliva PB, Hammill SC, Edwards WD: Diagnosis of ventricular wall rupture after acute myocardial infarction. J Am Coll Cardiol. 1993 Sep; 22(3): 720-6.

13. John H. Lunseth,Mona Ruwaldt. Pathogenesis of cardiac rupture due to myocardial infarction. Chest Journal. Nov 1956; 501-502. 